\title{
Matrix Isolation FTIR Spectroscopic and Theoretical Study of 3,3-Dichloro-1,1,1-Trifluoropropane (HCFC-243)
}

\author{
J. R. Lucena, Jr., ${ }^{\dagger} \dagger$ A. Sharma, ${ }^{\S}$ I. D. Reva, ${ }^{\S}$ R. M. C. U. Araújo, ${ }^{\dagger}$ E. Ventura, ${ }^{\dagger}$ \\ S. A. do Monte, ${ }^{\dagger}$ C. F. Braga ${ }^{\dagger}$ M. N. Ramos,$\stackrel{\perp}{\text { and R. Fausto } *, \S}$ \\ Departamento de Química, Universidade Federal da Paraíba, 58059-900 João Pessoa-PB, Brazil, \\ Departamento de Química, Universidade of Coimbra, 3004-535 Coimbra, Portugal, and Departamento de \\ Química Fundamental, Universidade Federal de Pernambuco, 50739-901-Recife-PE, Brazil
}

Received: August 18, 2008; Revised Manuscript Received: September 30, 2008

\begin{abstract}
The molecular structure and infrared spectrum of the atmospheric pollutant 3,3-dichloro-1,1,1-trifluoropropane (HCFC-243) were characterized experimentally and theoretically. The theoretical calculations show the existence of two conformers, with the gauche $(\mathrm{G})$ and trans $(\mathrm{T})$ orientation around the HCCC dihedral angle. Conformer $\mathrm{G}$ was calculated to be more stable than form $\mathrm{T}$ by more than $10 \mathrm{~kJ} \mathrm{~mol}^{-1}$. In consonance with the large predicted relative energy of conformer $\mathrm{T}$, only the $\mathrm{G}$ form was identified spectroscopically in cryogenic argon $(10 \mathrm{~K})$ and xenon $(20 \mathrm{~K})$ matrices prepared from room-temperature equilibrium vapor of the compound. The observed infrared spectra of the matrix-isolated HCFC-243 were interpreted with the aid of high-level density functional theory calculations and normal coordinate analysis. For experimental identification of the weakest IR absorption bands, the spectrum of HCFC-243 in the neat solid state at $145 \mathrm{~K}$ was obtained. This spectrum also confirmed the sole presence of the G conformer in the sample. Natural bond orbital and atomic charge analyses were carried out for the two conformers to shed light on the most important intramolecular interactions in the two conformers, in particular those responsible for their relative stability.
\end{abstract}

\section{Introduction}

Hydrochlorofluorocarbons (HCFCs) and hydrofluorocarbons (HFCs) were believed to be the appropriate/ideal substituents for chlorofluorocarbons (CFC's), because they have a lesser impact on the ozone layer than $\mathrm{CFCs},{ }^{1-4}$ and thus had been replacing CFCs slowly. However, both HCFCs and HFCs do contribute significantly to the global warming ${ }^{5,6}$ and, despite the fact that they are less destructive for the ozone layer than CFCs, regulations on their global usage were designed ${ }^{7}$ and employed to eliminate their production and use by 2020.8

One of the HCFCs that fall under Montreal Protocol ${ }^{7}$ is 3,3-dichloro-1,1,1-trifluoropropane (HCFC-243), which is also an important precursor of the agricultural intermediate trichlorotrifluoropropane (HCFC-233). In the present study, the structure and vibrational spectrum of this potential atmospheric hazard were studied by a combined matrix-isolation infrared spectroscopy and molecular orbital calculations approach. Several studies $^{9-12}$ have been devoted to understand the atmospheric chemistry of some related compounds; however, we are not aware of any report on HCFC-243. A careful structural and spectroscopic investigation of this compound is certainly relevant for subsequent studies on its atmospheric chemical behavior as well as on the general chemical reactivity of HCFC's in atmosphere.

\section{Experimental and Computational Methods}

Computational Details. All calculations in this work were carried out using Gaussian 03. ${ }^{13}$ Molecular geometries were

\footnotetext{
* Corresponding author. E-mail: rfausto@ci.uc.pt.

$\dagger$ Universidade Federal da Paraíba.

\$ Permanent address: Departamento de Química, Universidade Estadual da Paraíba, 58101-001 - Campina Grande - PB - Brazil.

$\S$ University of Coimbra.

${ }^{\perp}$ Universidade Federal de Pernambuco.
}

optimized at the DFT level, with the three-parameter B3LYP density functional, which includes Becke's gradient exchange correction, ${ }^{14}$ the Lee, Yang, Parr correlation functional, ${ }^{15}$ and the Vosko, Wilk, and Nusair correlation functional, ${ }^{16}$ as well as at the second-order Møller-Plesset (MP2) ${ }^{17}$ level. A number of different basis sets, like 6-31G(d,p), 6-31++G(d,p), $6-311++\mathrm{G}(\mathrm{d}, \mathrm{p}), 6-311++\mathrm{G}(2 \mathrm{~d}, 2 \mathrm{p}), 6-311++\mathrm{G}(3 \mathrm{df}, 3 \mathrm{pd}),{ }^{18,19}$ aug-cc-PVDZ, and aug-cc-PVTZ, were used for comparison purposes. Geometry optimizations were followed by the calculation of vibrational spectra at the same theory level. The nature of the obtained stationary points was checked through the analysis of the corresponding Hessian matrices.

Normal coordinate analysis was performed in the internal coordinates space, as described by Schachtshneider and Mortimer, ${ }^{20}$ using the structural data and Cartesian force constants resulting from the DFT(B3LYP)/aug-cc-PVTZ calculations. The Cartesian force constants were converted to the space of symmetry coordinates described in Table S1 (see the Supporting Information) in order to allow for calculation of the normal modes of vibration and their respective PEDs. The program used to carry these calculations was a non commercial locally developed program. Most of the internal coordinates used in this analysis were defined according to the recommendations of Pulay et al. ${ }^{21}$ However, an alternative set of coordinates was used for the $\mathrm{CCl}_{2} \mathrm{H}$ group, providing a better description of the vibrations of this fragment.

Throughout this manuscript, nonscaled frequencies are used, because a linear fitting of the calculated wavenumbers for the experimentally relevant conformer $(G)$ to the corresponding experimentally observed values yields a scale factor of 0.999 . In this case, use of scaled (by a single scale factor) or nonscaled calculated frequencies is equivalent in practice. Calculated intensities are those obtained with Gaussian 03. 
Natural Bond Orbital analysis was undertaken using the NBO 3 code, as implemented in Gaussian 03.

Experimental Details. HCFC-243 was provided by ABCR $\mathrm{GmbH} \& \mathrm{Co.KG}$ (purity 99\%). Prior to usage, the compound was additionally purified by using the standard freeze-pumpthaw technique and the cell with the compound was further pumped at room temperature to remove volatile impurities.

Two different approaches were used to prepare the matrixisolated compound. In the first approach, HCFC-243 vapor was premixed with xenon (N48, supplied by Air Liquide) in a molar ratio of 1:1000. In the second approach, HCFC-243 was deposited onto the optical substrate from a dedicated line. This line consisted of a Knudsen cell, whose nozzle was kept at room temperature and the sample compartment was cooled down to $-97{ }^{\circ} \mathrm{C}$ (by immersing the ampule containing the compound into a Dewar vessel with melting methanol). This allowed the saturated vapor pressure over the compound to be reduced and the metering function of the valve to be improved, thus allowing a smooth deposition. The host matrix gas was coming from a separate line and was codeposited using the standard manometric procedure, without further purification. In the latter case, argon (N60, supplied by Air Liquide) was used as the matrix gas.

A CsI window was used as optical substrate for the matrices. Its temperature was stabilized at $10 \mathrm{~K}$ for the argon matrix and at $20 \mathrm{~K}$ for the xenon matrix. This temperature was measured directly at the sample holder by a silicon diode sensor connected to a digital controller (Scientific Instruments, model 9650-1), with accuracy of $\pm 0.1 \mathrm{~K}$. The low-temperature equipment was based on a closed-cycle helium refrigerator (APD Cryogenics) with a DE-202A expander.

Additional experiments were carried out in the neat solid state and gas phase. In the solid state experiments, the compound was deposited on the CsI window of the cryostat, while the substrate was kept at a temperature of $145 \mathrm{~K}$. At this substrate temperature, the obtained film of the compound has a high degree of crystallinity. At higher substrate temperatures, no condensation of HCFC-243 on the cold window occurred. The spectra of the solid samples were collected at different temperatures in the range $145-10 \mathrm{~K}$. The input system for deposition of the neat crystalline film of HCFC-243 as well as for obtaining the gas phase spectrum (Figure S1 in the Supporting Information) was the same Knudsen cell used for the argon matrix experiments, the only difference being that in this case no argon was codeposited. In these experiments, the valve nozzle was also kept at room temperature (ca. $25^{\circ} \mathrm{C}$ ) during deposition.

The infrared spectra were registered with $0.5 \mathrm{~cm}^{-1}$ resolution, in the range $4000-400 \mathrm{~cm}^{-1}$, using a Mattson (Infinity 60AR Series) Fourier-transform spectrometer, equipped with a deuterated triglycine sulfate (DTGS) detector and a $\mathrm{KBr}$ beamsplitter. The sample compartment of the spectrometer was modified in order to couple it with the cryostat head and allow purging of the instrument by a stream of dry nitrogen to remove water vapor and $\mathrm{CO}_{2}$.

Recent studies on 1,2-dichloropropane 22 showed that this compound undergoes photochemically induced conformational interconversion when isolated in low temperature xenon matrices. Attempts to investigate the photochemical reactivity of HCFC-243 were also made in the present study using two techniques described elsewhere. ${ }^{23,24}$ However, no changes in the experimental spectra of the matrix-isolated HCFC-243 could be induced by broadband UV-irradiation ${ }^{23}[\lambda>235 \mathrm{~nm}$; irradiating with a $\mathrm{Hg}(\mathrm{Xe})$ lamp through the cryostat $\mathrm{KBr}$ window], nor by broadband infrared irradiation (using an

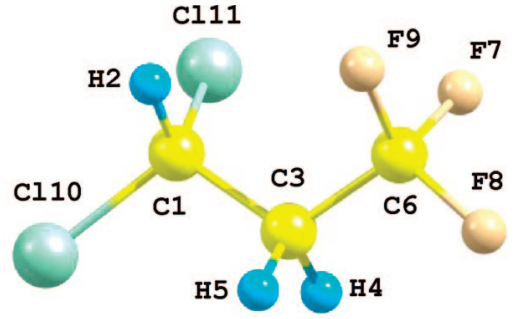

Gauche $\mathrm{H}-\mathrm{C}-\mathrm{C}-\mathrm{C}$

(G)

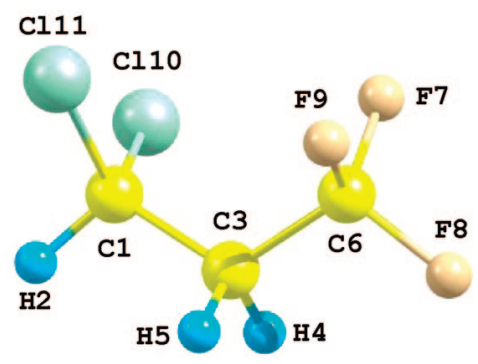

Trans $\mathrm{H}-\mathrm{C}-\mathrm{C}-\mathrm{C}$

(T)

Figure 1. Molecular structures of HCFC-243 conformers, with atom numbering.

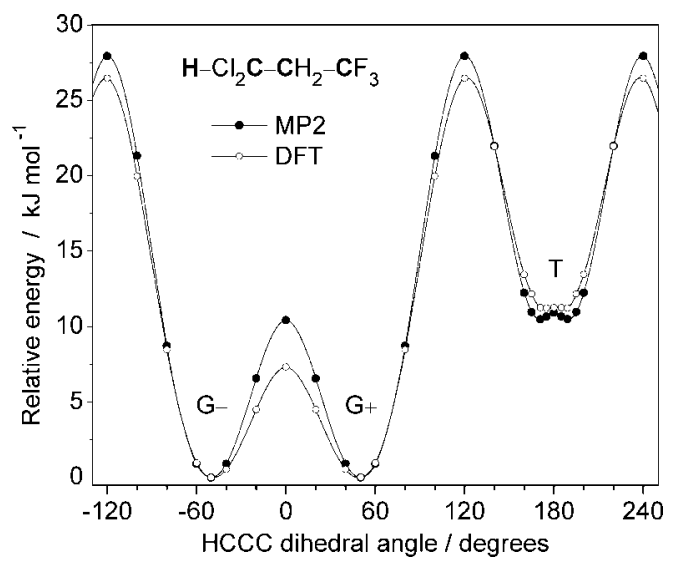

Figure 2. Results of the relaxed potential energy scan around the $\mathrm{H}_{(2)}-\mathrm{C}_{(1)}-\mathrm{C}_{(3)}-\mathrm{C}_{(6)}$ dihedral angle (HCCC) in HCFC-243, calculated at the DFT/B3LYP (white circles) and MP2 (black circles) levels of theory with the $6-311++G(d, p)$ basis set. Energy of the degenerateby-symmetry gauche conformers $(\mathrm{G}+; \mathrm{G}-)$ was chosen as the relative zero level.

electrically heated kanthal wire ${ }^{24}$ ). This high photochemical stability is certainly relevant to the atmospheric chemistry of HCFC-243.

\section{Results and Discussion}

Structural Results and General Description of the Vibrational Spectra. The molecular structure of HCFC-243, along with the atom numbering, is given in Figure 1. The main conformationally relevant degree of freedom in HCFC-243 is related with the internal rotation about the $\mathrm{C}_{(1)}-\mathrm{C}_{(3)}$ bond, which results in different conformers.

Relaxed potential energy scan as a function of the $\mathrm{H}-\mathrm{C}_{(1)}-\mathrm{C}_{(3)}-\mathrm{C}$ dihedral angle was calculated at both the DFT(B3LYP)/6-311++G(d,p) and MP2/6-311++G(d,p) levels of theory. As can be seen from Figure 2, the obtained potential energy profile exhibits three minima, $\mathrm{G}_{-}^{-}, \mathrm{G}+$, and $\mathrm{T}$, the letters $\mathrm{G}$ and $\mathrm{T}$ being abbreviations for gauche and trans, respectively. 


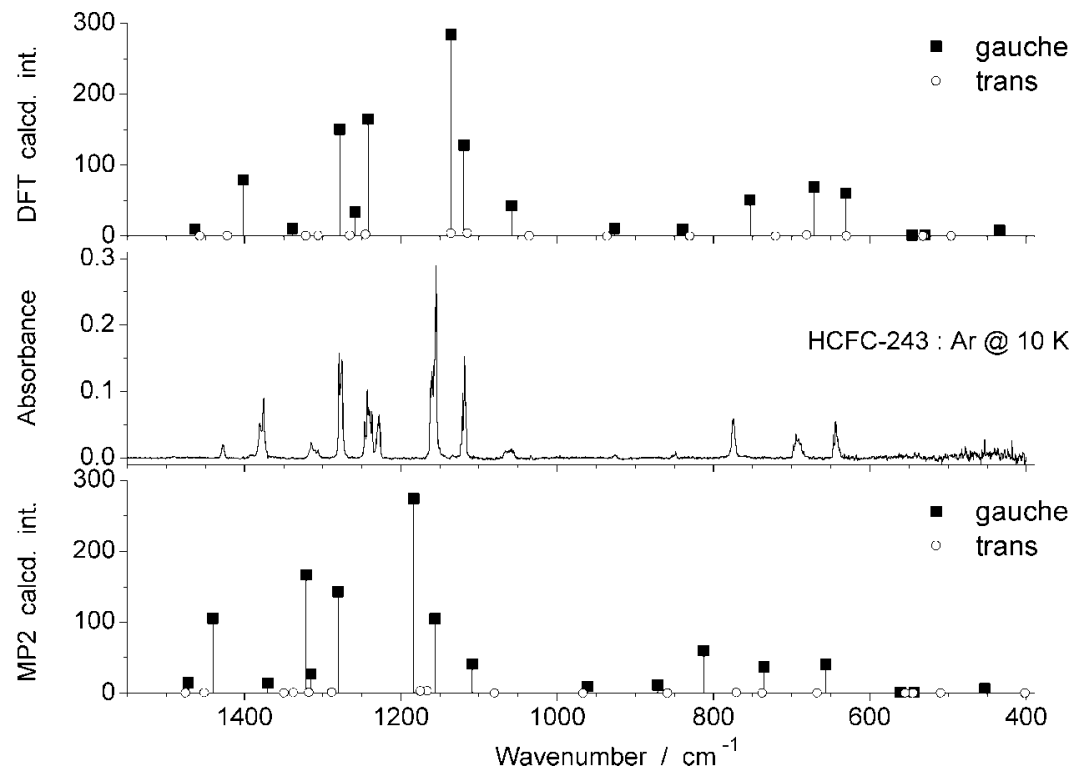

Figure 3. Experimental FTIR spectrum of HCFC-243 isolated in an argon matrix at $10 \mathrm{~K}$ (middle) compared with the theoretical spectra of the two conformers calculated at the DFT(B3LYP)/6-311++G(d,p) (top) and MP2/6-311++G(d,p) (bottom) levels. The calculated wavenumbers were not scaled and the calculated intensities were weighted by the equilibrium Boltzmann populations of the two conformers at $298.15 \mathrm{~K}$.

Two of these minima, $\mathrm{G}-$ and $\mathrm{G}+$, are degenerate by symmetry and spectroscopically equivalent. The $\mathrm{H}-\mathrm{C}_{(1)}-\mathrm{C}_{(3)}-\mathrm{C}$ dihedral angle was calculated to be $50.3^{\circ}$ (MP2) and $48.5^{\circ}$ (DFT), for conformer $\mathrm{G}+$, and $170.9^{\circ}(\mathrm{MP} 2)$ and $176.8^{\circ}(\mathrm{DFT})$, for conformer $\mathrm{T}$. In the case of the $\mathrm{T}$ conformer, the situation is slightly more complex since the calculations predict a doublewell potential with a very small energy barrier at the symmetric structure $\left[\sim 0.4 \mathrm{~kJ} \mathrm{~mol}^{-1}\right.$ (MP2) and ca. $0.1 \mathrm{~kJ} \mathrm{~mol}^{-1}$ (DFT)]. Nevertheless, this energy barrier is calculated to be slightly above the zero-point vibrational level associated with the isomerization coordinate at the minimum. Of course, the exact form of the potential near the T form is uncertain, because the energy values involved are within the error of the theoretical methods. However, whether the $\mathrm{T}$ conformer corresponds in reality to a single minimum or a double minimum is not relevant from the experimental point of view. Indeed, let us take for example the MP2 data: the calculated $\Delta H^{\circ}$ between the conformers is $10.8 \mathrm{~kJ} \mathrm{~mol}^{-1}$; the statistical weight of the $\mathrm{G}$ conformer is 2 ; if we assume that the $\mathrm{T}$ conformer corresponds to a single minimum, then its statistical weight is 1 and the $\mathrm{G}: \mathrm{T}$ population ratio is 99.4:0.6. If we assume that the $\mathrm{T}$ conformer corresponds to a double minimum, then its statistical weight is 2 and the G:T population ratio is 98.7:1.3. In both cases, the population ratio is ca. $99: 1$, i.e., the population of the $\mathrm{T}$ conformer is too low to be detectable under the experimental conditions used. So, in practical terms, the distinction between a single or double minimum around the $\mathrm{T}$ conformer does not influence the results we used in our analysis of the data.

Figure 3 shows the calculated infrared spectra of the $G$ and $\mathrm{T}$ conformers, where the calculated intensities were scaled by their equilibrium populations, compared with the experimental spectrum of HCFC-243 isolated in an argon matrix. The population of the $\mathrm{T}$ conformer is negligibly small and, in consonance with the theoretical predictions, the signature of the $\mathrm{G}$ conformer is the only one that can be distinguished in the experimental spectrum. Comparison between the experimental and calculated data also shows the overall good performance of both DFT(B3LYP) and MP2 methods, with the DFT calculations reproducing the experimental results only slightly better than the MP2 ones.

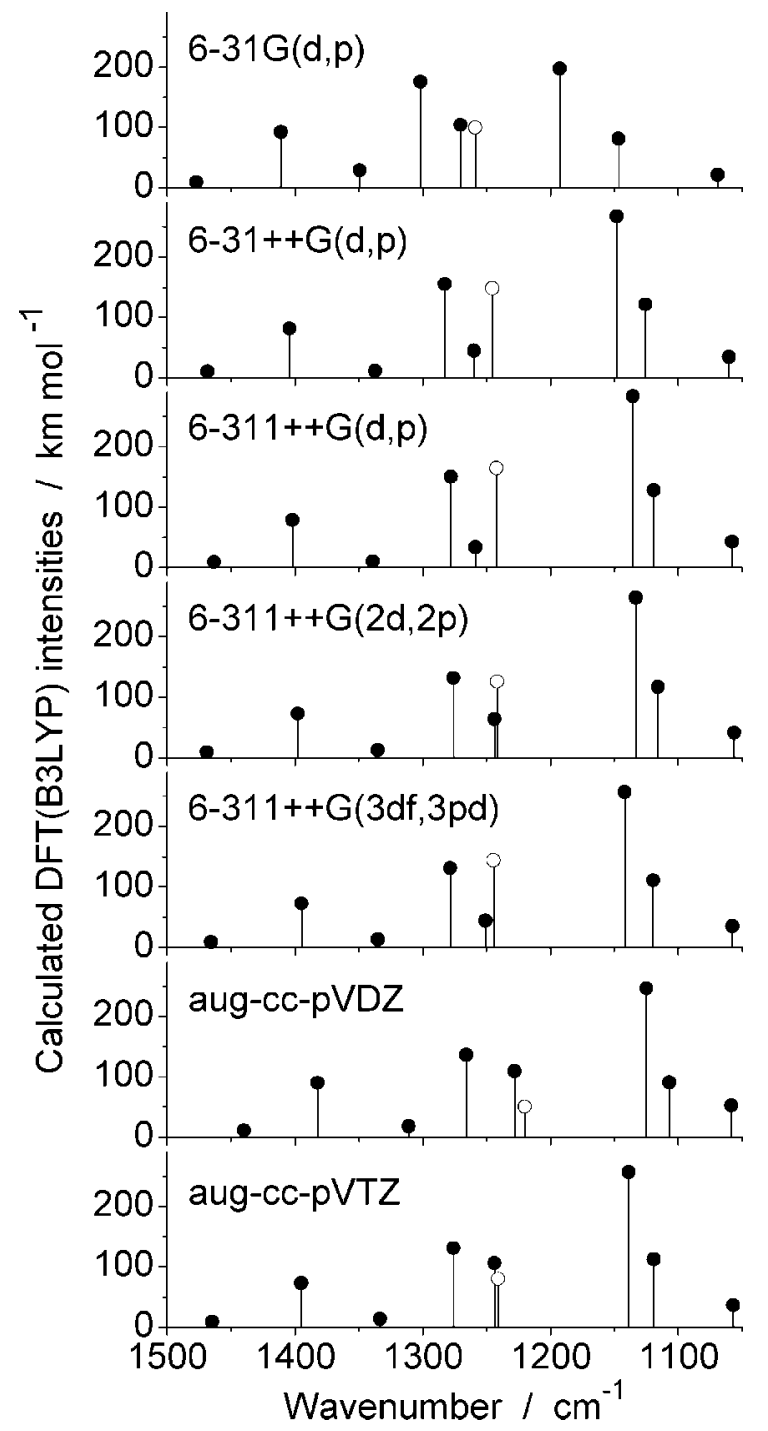

Figure 4. Theoretical spectra $\left(1500-1050 \mathrm{~cm}^{-1}\right.$ range) of the $\mathrm{G}$ conformer of HCFC-243 calculated at the DFT(B3LYP) level with different basis sets. 


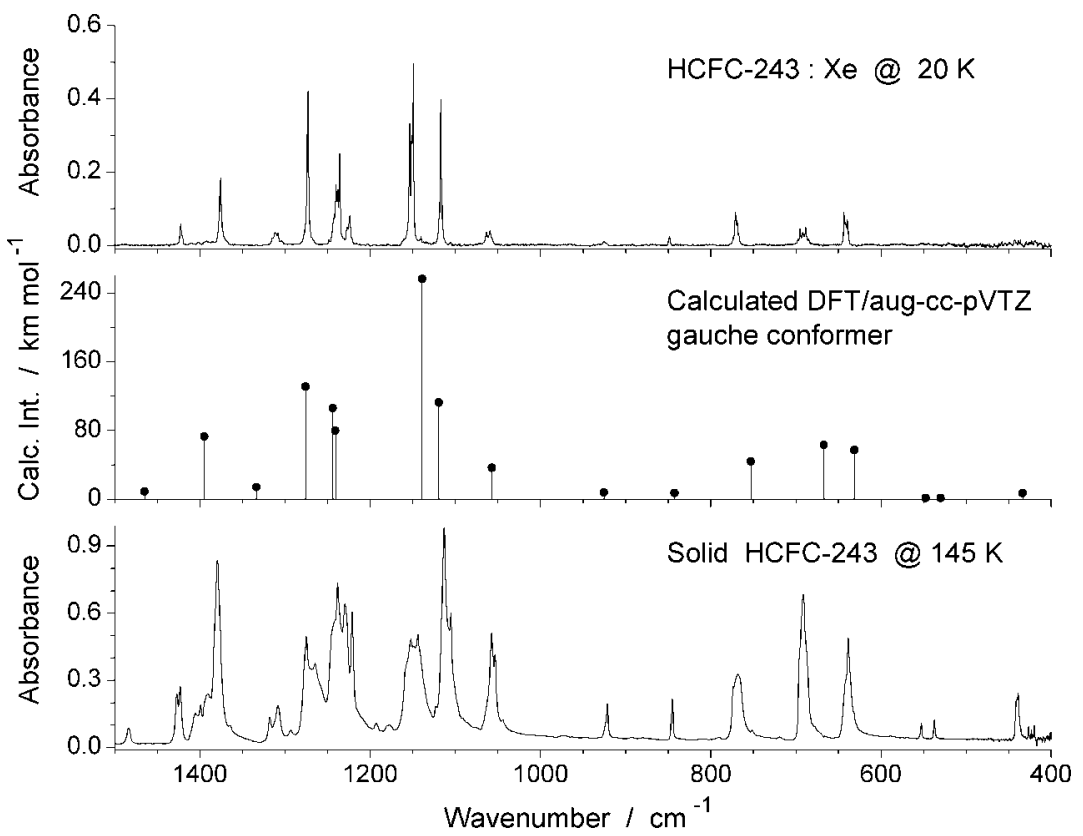

Figure 5. Experimental FTIR spectrum of HCFC-243 isolated in a xenon matrix at $20 \mathrm{~K}$ (top) compared with the theoretical spectrum of the G conformer calculated at the DFT(B3LYP)/aug-cc-pVTZ level (middle) and the experimental spectrum of the HCFC-243 neat solid at $145 \mathrm{~K}$.

TABLE 1: Experimentally Observed FTIR Spectrum (Ar matrix, $T=10 \mathrm{~K}$ and Xe matrix, $T=20 \mathrm{~K}$ ) and Theoretical Vibrational Frequencies $\left(\omega, \mathrm{cm}^{-1}\right)$, Infrared Intensities $\left(I, \mathrm{~km} \mathrm{~mol}^{-1}\right)$ and Potential Energy Distributions (PED) for HCFC-243 Monomer (conformer G) ${ }^{a}$

\begin{tabular}{|c|c|c|c|c|c|c|}
\hline \multicolumn{2}{|c|}{ observed $(\mathrm{Ar}, T=10 \mathrm{~K})$} & \multicolumn{2}{|c|}{ observed $(\mathrm{Xe}, T=20 \mathrm{~K})$} & \multicolumn{3}{|r|}{ calculated DFT(B3LYP)/aug-cc-pVTZ } \\
\hline$v$ & $I^{b}$ & $v$ & $I^{b}$ & $\omega$ & $I$ & $\operatorname{PED}^{c}(\%)$ \\
\hline & & & & 3157.1 & 0.8 & $v(\mathrm{C}-\mathrm{H})(94)$ \\
\hline $3024.6^{d}$ & & & & 3078.1 & 0.6 & $v\left(\mathrm{CH}_{2}\right)_{\mathrm{s}}(98)$ \\
\hline 1427.8 & 15.8 & 1422.7 & 23.8 & 1464.7 & 9.0 & $\delta\left(\mathrm{CH}_{2}\right)(100)$ \\
\hline 1375.5 & 87.9 & 1375.1 & 83.7 & 1394.9 & 72.9 & $\mathrm{w}\left(\mathrm{CH}_{2}\right)(67), v\left(\mathrm{C}_{(3)}-\mathrm{C}_{(6)}\right)(10)$ \\
\hline 1314.7 & 32.8 & 1311.1 & 33.6 & 1333.4 & 14.0 & $\operatorname{tw}\left(\mathrm{CH}_{2}\right)(52), \delta\left(\mathrm{H}-\mathrm{C}-\mathrm{Cl}_{(11)}\right)(27)$ \\
\hline 1242.9 & 167.0 & 1235.9 & 201.3 & 1243.8 & 106.1 & $\delta\left(\mathrm{H}-\mathrm{C}-\mathrm{Cl}_{(11)}\right)(37), v\left(\mathrm{C}_{(3)}-\mathrm{C}_{(6)}\right)(11), v\left(\mathrm{CF}_{3}\right)_{\mathrm{s}}(11)$ \\
\hline 1154.9 & 251.1 & $\begin{array}{l}1224.2 \\
1153.1 \\
1149.1\end{array}$ & 235.8 & $\begin{array}{l}1240.9 \\
1138.8\end{array}$ & $\begin{array}{r}79.8 \\
256.3\end{array}$ & $\begin{array}{l}\delta\left(\mathrm{H}-\mathrm{C}-\mathrm{Cl}_{(10)}\right)(66) \\
v\left(\mathrm{CF}_{3}\right)_{\text {as }}(61)\end{array}$ \\
\hline 1118.3 & 90.4 & 1116.8 & 107.9 & 1119.2 & 112.6 & $v\left(\mathrm{CF}_{3}\right)_{\mathrm{as}^{\prime}}(33), \operatorname{tw}\left(\mathrm{CH}_{2}\right)(20), \gamma\left(\mathrm{CH}_{2}\right)(12)$ \\
\hline 1060.2 & 29.5 & 1063.3 & 30.8 & 1057.0 & 36.5 & $v\left(\mathrm{C}_{(1)}-\mathrm{C}_{(3)}\right)(66), v\left(\mathrm{CF}_{3}\right)_{\mathrm{as}^{\prime}}(11)$ \\
\hline 925.7 & 7.7 & 925.4 & 4.4 & 925.1 & 7.8 & $\gamma\left(\mathrm{CH}_{2}\right)(53), v\left(\mathrm{CF}_{3}\right)_{\mathrm{as}^{\prime}}(24)$ \\
\hline $553.1^{d}$ & & & & 547.4 & 1.2 & $\delta\left(\mathrm{CF}_{3}\right)_{\text {as }}(49), v\left(\mathrm{CF}_{3}\right)_{\text {as }}(12)$ \\
\hline $538.5^{d}$ & & & & 529.7 & 1.5 & $\delta\left(\mathrm{CF}_{3}\right)_{\mathrm{as}^{\prime}}(66)$ \\
\hline $439.8^{d}$ & & & & 433.6 & 7.1 & $\gamma\left(\mathrm{C}-\mathrm{C}-\mathrm{Cl}_{(11)}\right)(32), \delta\left(\mathrm{CF}_{3}\right)_{\text {as }}(25), \gamma\left(\mathrm{CF}_{3}\right)(20)$ \\
\hline n.i. & & & & 363.4 & 1.5 & $\gamma^{\prime}\left(\mathrm{CF}_{3}\right)(60), \delta\left(\mathrm{CF}_{3}\right)_{\mathrm{as}^{\prime}}(12)$ \\
\hline n.i. & & & & 328.4 & 0.2 & $\delta\left(\mathrm{CCl}_{2}\right)(33), v\left(\mathrm{C}-\mathrm{Cl}_{(10)}\right)(20), v\left(\mathrm{C}-\mathrm{Cl}_{(11)}\right)(10)$ \\
\hline n.i. & & & & 248.6 & 1.0 & $\gamma\left(\mathrm{C}-\mathrm{C}-\mathrm{Cl}_{(11)}\right)(33), \gamma\left(\mathrm{CF}_{3}\right)(26), \gamma\left(\mathrm{C}-\mathrm{C}-\mathrm{Cl}_{(10)}\right)$ \\
\hline n.i. & & & & 232.1 & 0.8 & $\delta\left(\mathrm{CCl}_{2}\right)(39), \gamma\left(\mathrm{C}-\mathrm{C}-\mathrm{Cl}_{(10)}\right)$ \\
\hline n.i. & & & & 139.8 & 2.9 & $\delta(\mathrm{C}-\mathrm{C}-\mathrm{C})(58), \gamma\left(\mathrm{C}-\mathrm{C}-\mathrm{Cl}_{(10)}\right)(17), \gamma\left(\mathrm{CF}_{3}\right)$ \\
\hline n.i. & & & & 96.6 & 2.1 & $\tau(\mathrm{CC})_{\text {asym }}(98)$ \\
\hline n.i. & & & & 31.7 & 0.3 & $\tau(\mathrm{CC})_{\mathrm{sym}}(98)$ \\
\hline
\end{tabular}

${ }^{a}$ Definition of symmetry coordinates is given in Figure 1 for atom numbering. Abbreviations: $v$, stretching; $\delta$, bending; $\gamma$, rocking; w, wagging; tw, twisting; $\tau$, torsion; as, antisymmetric; s, symmetric; n.i., not investigated. ${ }^{b}$ Relative integrated intensities. ${ }^{c}$ PED's lower than $10 \%$ are not included. ${ }^{d}$ Value taken from the spectrum of the neat compound in the solid state.

The largest discrepancy between the calculated and the experimental data was found in the $1300-1100 \mathrm{~cm}^{-1}$ spectral region. To understand the reason of this discrepancy, and to achieve a better theoretical description of the experimental data, we calculated the theoretical spectrum of the most stable HCFC243 conformer at the DFT(B3LYP) level with different basis sets. The $1500-1050 \mathrm{~cm}^{-1}$ regions of these spectra are graphically compared in Figure 4. From this comparison, it is obvious that a satisfactory description can be achieved only with a basis set including diffuse functions. The theoretical spectrum calculated with the $6-31 \mathrm{G}(\mathrm{d}, \mathrm{p})$ basis set, without diffuse functions, is the only outlier. Among the remaining basis sets, 
TABLE 2: Selected Natural Bond Orbitals of Conformer G, Obtained from the MP2/6-311++G(d,p) Calculations

\begin{tabular}{|c|c|c|c|c|}
\hline \multirow{2}{*}{$\begin{array}{c}\text { bond orbital }^{a} \\
\mathrm{~T}(\mathrm{~A}-\mathrm{B})\end{array}$} & \multirow[b]{2}{*}{ occupancy $^{b}(e)$} & \multicolumn{2}{|c|}{ coefficients } & \multirow[b]{2}{*}{ description } \\
\hline & & $\% \mathrm{~A}$ & $\% \mathrm{~B}$ & \\
\hline$\sigma\left(\mathrm{C}_{(1)}-\mathrm{C}_{(3)}\right)$ & 1.98992 & 50.69 & 49.31 & $0.7120 \mathrm{sp}^{(2.13)}+0.7022 \mathrm{sp}^{(2.47)} \mathrm{d}^{(0.03)}$ \\
\hline$\sigma\left(\mathrm{C}_{(1)}-\mathrm{Cl}_{(10)}\right)$ & 1.98951 & 46.62 & 53.38 & $0.6828 \mathrm{sp}^{(3.69)} \mathrm{d}^{(0.02)}+0.7306 \mathrm{sp}^{(5.18)} \mathrm{d}^{(0.04)}$ \\
\hline$\sigma\left(\mathrm{C}_{(1)}-\mathrm{Cl}_{(11)}\right)$ & 1.98976 & 46.92 & 53.08 & $0.6850 \mathrm{sp}^{(3.63)} \mathrm{d}^{(0.02)}+0.7285 \mathrm{sp}^{(5.11)} \mathrm{d}^{(0.04)}$ \\
\hline$\sigma\left(\mathrm{C}_{(3)}-\mathrm{H}_{(4)}\right)$ & 1.97978 & 61.29 & 38.71 & $0.7829 \mathrm{sp}^{(3.20)} \mathrm{d}^{(0.01)}+0.6222 \mathrm{~s}$ \\
\hline$\sigma\left(\mathrm{C}_{(6)}-\mathrm{F}_{(7)}\right)$ & 1.99548 & 26.81 & 73.19 & $0.5178 \mathrm{sp}^{(3.54)} \mathrm{d}^{(0.03)}+0.8555 \mathrm{sp}^{(2.51)}$ \\
\hline$\sigma\left(\mathrm{C}_{(6)}-\mathrm{F}_{(8)}\right)$ & 1.99531 & 26.65 & 73.35 & $0.5162 \mathrm{sp}^{(3.57)} \mathrm{d}^{(0.03)}+0.8565 \mathrm{sp}^{(2.55)}$ \\
\hline$\sigma\left(\mathrm{C}_{(6)}-\mathrm{F}_{(9)}\right)$ & 1.99535 & 26.39 & 73.61 & $0.5137 \mathrm{sp}^{(3.68)} \mathrm{d}^{(0.03)}+0.8580 \mathrm{sp}^{(2.55)}$ \\
\hline $\mathrm{n}_{1}\left(\mathrm{~F}_{(7)}\right)$ & 1.99065 & & & $\mathrm{sp}^{(0.40)}$ \\
\hline $\mathrm{n}_{2}\left(\mathrm{~F}_{(7)}\right)$ & 1.96652 & & & $\mathrm{p}$ \\
\hline $\mathrm{n}_{3}\left(\mathrm{~F}_{(7)}\right)$ & 1.95350 & & & $\mathrm{p}$ \\
\hline $\mathrm{n}_{2}\left(\mathrm{~F}_{(9)}\right)$ & 1.96881 & & & $\mathrm{p}$ \\
\hline $\mathrm{n}_{3}\left(\mathrm{~F}_{(9)}\right)$ & 1.95655 & & & $\mathrm{p}$ \\
\hline $\mathrm{n}_{1}\left(\mathrm{Cl}_{(10)}\right)$ & 1.99552 & & & $\mathrm{sp}^{(0.22)}$ \\
\hline $\mathrm{n}_{2}\left(\mathrm{Cl}_{(10)}\right)$ & 1.97592 & & & $\mathrm{p}$ \\
\hline $\mathrm{n}_{3}\left(\mathrm{Cl}_{(10)}\right)$ & 1.96450 & & & $\mathrm{p}$ \\
\hline $\mathrm{n}_{1}\left(\mathrm{Cl}_{(11)}\right)$ & 1.99525 & & & $\mathrm{sp}^{(0.21)}$ \\
\hline $\mathrm{n}_{2}\left(\mathrm{Cl}_{(11)}\right)$ & 1.97487 & & & $\mathrm{p}$ \\
\hline $\mathrm{n}_{3}\left(\mathrm{Cl}_{(11)}\right)$ & 1.95967 & & & $\mathrm{p}$ \\
\hline $\mathrm{Ry}_{1} *\left(\mathrm{C}_{(6)}\right)$ & 0.01354 & & & $\mathrm{pd}^{(0.23)}$ \\
\hline $\mathrm{Ry}_{2} *\left(\mathrm{C}_{(6)}\right)$ & 0.01310 & & & $\mathrm{pd}^{(0.32)}$ \\
\hline$\sigma^{*}\left(\mathrm{C}_{(1)}-\mathrm{H}_{(2)}\right)$ & 0.03350 & 38.84 & 61.16 & $0.6232 \mathrm{sp}^{(2.92)} \mathrm{d}^{(0.01)}-0.7821 \mathrm{~s}$ \\
\hline$\sigma^{*}\left(\mathrm{C}_{(1)}-\mathrm{C}_{(3)}\right)$ & 0.02486 & 49.31 & 50.69 & $0.7022 \mathrm{sp}^{(2.13)}-0.7120 \mathrm{sp}^{(2.47)}$ \\
\hline$\sigma^{*}\left(\mathrm{C}_{(1)}-\mathrm{Cl}_{(10)}\right)$ & 0.03833 & 53.38 & 46.62 & $0.7306 \mathrm{sp}^{(3.69)} \mathrm{d}^{(0.02)}-0.6828 \mathrm{sp}^{(5.18)} \mathrm{d}^{(0.04)}$ \\
\hline
\end{tabular}

${ }^{a}$ The presented description is made in the space of the input atomic orbitals [as given by the $6-311++\mathrm{G}(\mathrm{d}, \mathrm{p})$ basis set used in the calculations]. The $\% \mathrm{~A}$ and $\% \mathrm{~B}$ values correspond to the contributions of the atomic orbitals of the two atoms forming a bond (by order of appearance in the corresponding entry in the first column) for the NBO orbitals extracted from the polarization coefficients given in the description of the NBO orbitals. See atom numbering in Figure $1 .{ }^{b}$ Occupancy is given with an exaggerated accuracy, as in the Gaussian output file.

all calculated spectra are qualitatively the same, both in terms of the relative calculated frequencies and intensities. There are, however, two vibrations around $1250-1220 \mathrm{~cm}^{-1}$, which were found to be extremely sensitive to the basis set used. In Figure 4 , one of these modes is marked by a white circle. As is clear from the figure, the relative frequency and intensity of this band and its immediate neighbor at the higher-frequency side depend very much on the basis set used. At the highest basis set employed, aug-cc-pVTZ, the frequencies of these two bands are predicted to coincide within 3 wavenumbers, which in the absence of molecular symmetry may lead, in practice, to sensitive changes in the frequencies of these two modes in response to changes in the molecular environment.

Indeed, the experimental feature observed in the 1250-1220 $\mathrm{cm}^{-1}$ region exhibits a very complicated profile (see Figure 3 ), and rather resembles a resonance multiplet than a band or a pair of bands because of undisturbed vibrations. These vibrations should then be particularly sensitive to changes in the chemical environment, since these changes usually lead to alterations in the equilibrium geometry and force constants of the studied system, and such changes may be sufficient to modify the interaction between the relevant quantum states appreciably. The spectrum in this region should then also change significantly under different experimental conditions. Similar behavior was experimentally observed, for example, for the Fermi-resonance multiplets of uracil isolated in matrices of different inert gases. ${ }^{25}$ To test this hypothesis for HCFC-243, we isolated the compound in a matrix of a different inert gas (xenon). The result is presented in Figure 5 and supports the proposed interpretation: comparing to the argon matrix (see Figure 3), in xenon matrix the shape of the $1250-1220 \mathrm{~cm}^{-1}$ feature becomes much narrower, whereas the shapes and widths of the remaining bands practically do not change.

Another possibility to change the environment for the studied molecule would be to study it as a neat solid. For molecules that do not establish strong intermolecular hydrogen bonds, the solid-state spectra are defined by the intramolecular structure of the compound and may strongly resemble the spectra of monomers. Such a situation was experimentally observed for example in the cases of pyrazine, pyrimidine, and pyridazine. ${ }^{26}$ As shown in Figure 5, this is also the case of HCFC-243; the infrared spectrum of the neat solid shows a good resemblance 
TABLE 3: Stabilization Energies for the Selected Orbital Pairs as Given by the Second-Order Perturbation Theory Analysis of Fock Matrix in NBO Basis for $G$ and T Conformers, Obtained from the MP2/6-311++G(d,p) Calculations $^{a}$

\begin{tabular}{llccc}
\hline $\begin{array}{c}\text { pair } \\
\text { name }\end{array}$ & $\begin{array}{c}\text { donor } \\
\mathrm{NBO}^{a}\end{array}$ & $\begin{array}{c}\text { acceptor } \\
\mathrm{NBO}^{a}\end{array}$ & $\begin{array}{c}\text { conformer } \\
\mathrm{G} \mathrm{E}(2)^{b}\end{array}$ & $\begin{array}{c}\text { conformer } \\
\mathrm{T} \mathrm{E}(2)^{b}\end{array}$ \\
\hline vicinal \\
I & $\mathrm{n}_{3}\left(\mathrm{~F}_{(7)}\right)$ & $\sigma^{*}\left(\mathrm{C}_{(6)}-\mathrm{F}_{(8)}\right)$ & 57.15 & 59.83 \\
II & $\mathrm{n}_{3}\left(\mathrm{~F}_{(7)}\right)$ & $\sigma^{*}\left(\mathrm{C}_{(6)}-\mathrm{F}_{(9)}\right)$ & 54.43 & 51.17 \\
III & $\mathrm{n}_{3}\left(\mathrm{~F}_{(8)}\right)$ & $\sigma^{*}\left(\mathrm{C}_{(6)}-\mathrm{F}_{(7)}\right)$ & 44.64 & 56.99 \\
IV & $\mathrm{n}_{3}\left(\mathrm{~F}_{(8)}\right)$ & $\sigma^{*}\left(\mathrm{C}_{(6)}-\mathrm{F}_{(9)}\right)$ & 60.84 & 45.65 \\
V & $\mathrm{n}_{3}\left(\mathrm{~F}_{(9)}\right)$ & $\sigma^{*}\left(\mathrm{C}_{(6)}-\mathrm{F}_{(7)}\right)$ & 47.49 & 47.74 \\
VI & $\mathrm{n}_{3}\left(\mathrm{~F}_{(9)}\right)$ & $\sigma^{*}\left(\mathrm{C}_{(6)}-\mathrm{F}_{(8)}\right)$ & 56.44 & 60.54 \\
VII & $\mathrm{n}_{3}\left(\mathrm{Cl}_{(10)}\right)$ & $\sigma^{*}\left(\mathrm{C}_{(1)}-\mathrm{Cl}_{(11)}\right)$ & 45.98 & 48.95 \\
VIII & $\mathrm{n}_{3}\left(\mathrm{Cl}_{(11)}\right)$ & $\sigma^{*}\left(\mathrm{C}_{(1)}-\mathrm{Cl}_{(10)}\right)$ & 50.46 & 50.29 \\
& & remote & & \\
IX & $\mathrm{n}_{2}\left(\mathrm{Cl}_{(10)}\right)$ & $\sigma^{*}\left(\mathrm{C}_{(3)}-\mathrm{C}_{(6)}\right)$ & 4.90 & \\
X & $\mathrm{n}_{2}\left(\mathrm{Cl}_{(11)}\right)$ & $\sigma^{*}\left(\mathrm{C}_{(3)}-\mathrm{H}_{(5)}\right)$ & 3.68 & \\
XI & $\mathrm{n}_{2}\left(\mathrm{Cl}_{(10)}\right)$ & $\sigma^{*}\left(\mathrm{C}_{(3)}-\mathrm{H}_{(5)}\right)$ & & 3.31 \\
XII & $\mathrm{n}_{2}\left(\mathrm{Cl}_{(11)}\right)$ & $\sigma^{*}\left(\mathrm{C}_{(3)}-\mathrm{H}_{(4)}\right)$ & & 2.97
\end{tabular}

${ }^{a}$ See atom numbering in Figure $1 .{ }^{b}$ Energies in $\mathrm{kJ} \mathrm{mol}^{-1}$. Sums of $\mathrm{E}(2)$ for vicinal and remote interactions are 417.43 and $8.58 \mathrm{~kJ}$ $\mathrm{mol}^{-1}$, respectively, in conformer $\mathrm{G}$ and 421.16 and $6.28 \mathrm{~kJ} \mathrm{~mol}^{-1}$ in conformer $\mathrm{T}$. The total NBO stabilizing interaction energies are 426.01 and $427.44 \mathrm{~kJ} \mathrm{~mol}^{-1}$, respectively, for $\mathrm{G}$ and $\mathrm{T}$ (see text for discussion of these values).

with the calculated and experimental data for monomers. Furthermore, the $1250-1220 \mathrm{~cm}^{-1}$ region is again represented by a broad and structured multiplet, suggesting once more the existence of strong interactions for vibrations absorbing in this region. The precise nature of these vibrations will be addressed below.

Assignment of the Spectra. The lowest energy conformer of $\mathrm{HCFC}-243$ (form $\mathrm{G}$ ) belongs to the $\mathrm{C}_{1}$ point group (see Figure 1) and has 27 vibrations, all formally active in infrared. The set of symmetry coordinates used in this study to carry out the normal coordinate calculations is given in Table $\mathrm{S} 1$ in the Supporting Information; the vibrational assignments, together with the PEDs resulting from the normal coordinate analysis are presented in Table 1.

Detailed assignment of the matrix-isolation IR spectra was facilitated by the sole presence of conformer $G$ in the samples. A comparison of the experimental and calculated spectra reveals that these spectra are similar regarding both the position and intensity of the bands. The most intense band according to the DFT(B3LYP) calculations has a unique contribution from the $v\left(\mathrm{CF}_{3}\right)_{\text {as }}$ coordinate and is predicted at $1138.8 \mathrm{~cm}^{-1}$ with intensity of $256 \mathrm{~km} \mathrm{~mol}^{-1}$. The corresponding peak in the spectra of matrix-isolated HCFC-243 appears at $1153.1 \mathrm{~cm}^{-1}$ (in argon). Other intense bands observed in the IR spectrum of matrix-isolated HCFC-243 appeared at 1375.5, 1279.1, and $1118.3 \mathrm{~cm}^{-1}$ (in argon), whereas their theoretical counterparts were predicted at $1394.9,1275.8$, and $1119.2 \mathrm{~cm}^{-1}$. The first and the last of these peaks were assigned to the wagging mode of the methylene group and one of the antisymmetric stretching vibrations of the trifluoromethyl group $\left[v\left(\mathrm{CF}_{3}\right)_{\mathrm{as}}\right]$, respectively; the peak at $1275.8 \mathrm{~cm}^{-1}$ corresponds to a very delocalized vibration with major contribution from the $\mathrm{C}-\mathrm{CF}_{3}$ fragment (see Table 1).

The two modes around $1240 \mathrm{~cm}^{-1}$ also have high intensities in infrared. The nature of these vibrations could be easily identified by visualization of the corresponding normal modes using a graphical interface. In agreement with this visualization, the symmetry coordinates were defined in a different way comparing to the recommendations of Pulay et al. ${ }^{21}$ This alternative definition confirmed the visualization and showed that these two predicted modes are due to two orthogonal $\delta(\mathrm{H}-\mathrm{C}-\mathrm{Cl})$ vibrations. As it was discussed above, these modes are involved in a strong interaction. A third component, which most probably also contributes to the complexity exhibited by this spectral region results from Fermi resonance between the $\delta(\mathrm{H}-\mathrm{C}-\mathrm{Cl})$ vibrations and the combination tone arising from two modes predicted at $691.1 \mathrm{~cm}^{-1}\left[v \mathrm{CCl}_{(11)}\right]$ and $553.1 \mathrm{~cm}^{-1}$ $\left[\delta\left(\mathrm{CF}_{3}\right)_{\mathrm{as}}\right]$.

The $553.1 \mathrm{~cm}^{-1}$ vibration was predicted to give rise to an infrared band with a very weak intensity (ca. $1 \mathrm{~km} \mathrm{~mol}^{-1}$; see Table 1), and its experimental counterpart was difficult to distinguish in the spectra of matrix-isolated samples. The same situation occurs for some other weakly absorbing modes [e.g., $v\left(\mathrm{CH}_{2}\right)_{\mathrm{s}}, \quad \delta\left(\mathrm{CF}_{3}\right)_{\mathrm{as}}, \quad \delta\left(\mathrm{CF}_{3}\right)_{\mathrm{as}}$; see Table 1$)$. However, the experimental frequencies corresponding to these theoretically predicted weak bands could be successfully identified in the spectrum of the neat solid at low temperature (Figure 5), and found to be in a very good agreement with the results of the calculations. It is also worth mentioning that the spectrum of the HCFC-243 crystal also conforms to the spectra of the G conformer only.

Analysis of Intramolecular Interactions. NBO and Charges. Because of the composition of the HCFC-243 molecule, with several electronegative atoms at relatively short distances from each other, repulsive intramolecular interactions can be anticipated to be dominant. It is, however, difficult guessing, for example, which are the main interactions causing the greater stability of the $\mathrm{G}$ conformer when compared with the $\mathrm{T}$ form. In the following discussion, an evaluation of the most important intramolecular interactions in HCFC-243 is done using NBO and charge-distribution analyses.

The NBO analysis is based on the MP2/6-311++G(d,p) wave functions. Filled NBOs, empty bond NBOs, and nonLewis Rydberg orbitals, as well as their interactions according to second-order perturbation theory analysis of the Fock matrix, are considered in this approach. ${ }^{27}$

The NBO analysis for G (Table 2) and T (see Table S2 in the Supporting Information) conformers produced essentially similar results, with only a few differences to note. For example, it is shown that the lone pair $\mathrm{n}_{2}$ of $\mathrm{Cl}_{(10)}$ has a pure $\mathrm{p}$-character in the $\mathrm{G}$ form, whereas in the $\mathrm{T}$ form, it is sp hybridized. Also, a comparison of the occupancies of the antibonding orbitals that take part in the remote interactions with chlorine lone pairs shows that their occupancies are higher in $G$ than in T. Below, we will discuss only some representative interactions, which for both conformers occur between lone electron pairs of chlorine and fluorine atoms and the antibonding $\sigma^{*}$ orbital localized on $\mathrm{CC}$ (in the case of $\mathrm{G}$ conformer) or $\mathrm{CH}$ (in the case of $\mathrm{T}$ conformer) bonds.

Table 3 shows the selected NBO interactions occurring in $\mathrm{G}$ and $\mathrm{T}$ conformers. The interactions shown in this table belong to two categories; vicinal and remote. The vicinal interactions lead to the highest stabilization energies. Nevertheless, the superposition of these energies does not explain the higher stability of conformer $G$ relatively to conformer $T$. On the contrary, the sum of these stabilizing energies favors conformer $\mathrm{T}$ by about $4 \mathrm{~kJ} \mathrm{~mol}^{-1}$. On the other hand, the remote interactions (see also Figure 6) are very weak, and though their stabilizing effect is slightly higher in form $G$ than in $T$, it is still not enough to explain the overall stability of $G$. These results indicate that other intramolecular effects than orbital interactions must be prevalent in the studied compound. As already 


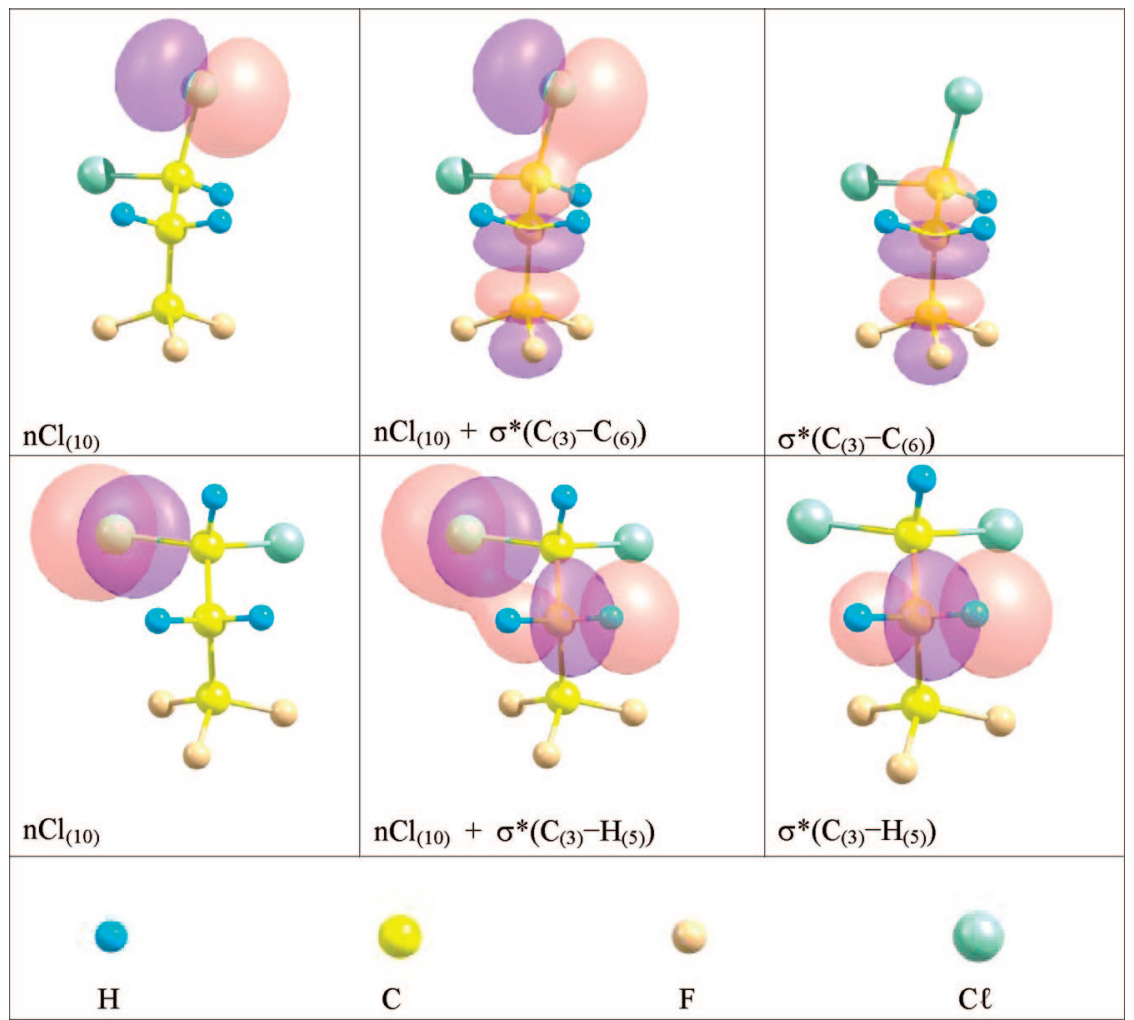

Figure 6. Electron density surfaces of selected preorthogonalized NBOs of HCFC-243 calculated at the MP2/6-311++G(d,p) level. Different colors correspond to opposite signs. Isovalues of the electron densities are equal to $0.02 e$. the figure shows the most relevant remote orbital interactions, corresponding to conformational change: IX (first row, form G) and XI (second row, form T), as given in Table 4. The donor orbitals are depicted in Column 1 and the acceptor orbitals in column 3. Column 2 shows the result of summation of the donor and acceptor orbitals. Bottom row represents color codes: blue, hydrogen; yellow, carbon; brown, fluorine; green, chlorine.

TABLE 4: APT Charges (e) Obtained from the MP2/ 6-311 $++\mathbf{G}(\mathbf{d}, \mathbf{p})$ Calculations ${ }^{a}$

\begin{tabular}{lrr}
\hline atom $^{a}$ & conformer $\mathrm{G}$ & conformer T \\
\hline $\mathrm{C}_{(1)}$ & 0.651 & 0.663 \\
$\mathrm{H}_{(2)}$ & -0.020 & -0.039 \\
$\mathrm{C}_{(3)}$ & -0.136 & -0.127 \\
$\mathrm{H}_{(4)}$ & 0.049 & 0.037 \\
$\mathrm{H}_{(5)}$ & 0.035 & 0.031 \\
$\mathrm{C}_{(6)}$ & 1.658 & 1.617 \\
$\mathrm{~F}_{(7)}$ & -0.537 & -0.526 \\
$\mathrm{~F}_{(8)}$ & -0.584 & -0.572 \\
$\mathrm{~F}_{(9)}$ & -0.551 & -0.531 \\
$\mathrm{Cl}_{(10)}$ & -0.293 & -0.278 \\
$\mathrm{Cl}_{(11)}$ & -0.271 & -0.273
\end{tabular}

${ }^{a}$ See atom numbering in Figure 1.

TABLE 5: Energies for Intramolecular Coulombic Interactions $\left(\mathrm{kJ} \mathrm{mol}^{-1}\right)$ for Selected Pairs of Atoms Estimated from the APT Charges Calculated at the B3LYP/ aug-cc-pVTZ and MP2/6-311 $++G(d, p)$ Levels of Theory

\begin{tabular}{|c|c|c|c|c|}
\hline & \multicolumn{2}{|c|}{ DFT(B3LYP)/aug-cc-pVTZ } & \multicolumn{2}{|c|}{$\mathrm{MP} 2 / 6-311++\mathrm{G}(\mathrm{d}, \mathrm{p})$} \\
\hline & $F_{(7)}$ & $F_{(9)}$ & $F_{(7)}$ & $\mathrm{F}_{(9)}$ \\
\hline conformer $\mathrm{G}$ & & & & \\
\hline $\mathrm{H}_{(2)}$ & 2.51 & 3.43 & 4.42 & 6.80 \\
\hline $\begin{array}{l}\mathrm{Cl}_{(11)} \\
\text { conformer } \mathrm{T}\end{array}$ & 66.95 & 56.63 & 66.04 & 55.43 \\
\hline $\mathrm{Cl}_{(10)}$ & 67.91 & 52.47 & 67.23 & 48.30 \\
\hline $\mathrm{Cl}_{(11)}$ & 52.47 & 67.91 & 57.16 & 66.23 \\
\hline
\end{tabular}

mentioned, charge repulsions appear to be the natural candidate. These can be evaluated from the analysis of the Coulombic forces within the molecule.
The calculated Mulliken charges ${ }^{28}$ NBO charges, ${ }^{29}$ and atomic polar tensor (APT) charges ${ }^{30}$ were then obtained at the MP2/6-311++G(d,p) level of approximation (see Table S3 in the Supporting Information). As shown in Table S3, these three sets of charges differ considerably. Because Mulliken charges fail to give a useful and reliable characterization of the charge distribution in many cases, ${ }^{29}$ and NBO may lead to exaggerated $\mathrm{C}-\mathrm{H}$ bond dipoles, ${ }^{31}$ APT charges (Table 4) were used in the evaluation of the Coulombic forces within the HCFC-243 molecule. The APT charge is related to the trace of the corresponding atomic polar tensor (tensor of the derivatives of dipole moment with respect to atomic Cartesian coordinates); $; 0$ the resulting populations provide insight into the electron distribution in molecules that is not distorted by an arbitrary choice of the reference basis set.

The interaction energies $E_{i j}$ were calculated according to the formula

$$
E_{i j}=\left(4 \pi \varepsilon_{0}\right)^{-1} \mathbf{q}_{i} \mathbf{q}_{j} \mathbf{r}^{-1}
$$

where $\varepsilon_{0}$ is the value of the dielectric permittivity for vacuum and $\mathbf{q}_{i}, \mathbf{q}_{j}$ are the calculated charges for atoms $i$ and $j$, whose nuclei are separated by the distance $\mathbf{r}$.

As it follows from Table 4, the HCFC-243 molecule has two strongly charged negative regions, the $\mathrm{CF}_{3}$ and $\mathrm{CCl}_{2} \mathrm{H}$ groups. It can be assumed that interactions within these groups are the same in both conformers. On the other hand, the structure of the conformers (see Figure 1) suggests that their relative energies should be determined by the different repulsive interactions between the terminal groups, which correspond to the negatively charged molecular domains. It can be expected that these repulsive interactions are strongest between the pairs of atoms 
that are located closer to each other. In the case of the $\mathrm{G}$ conformer, these are the pairs $\left(\mathrm{Cl}_{(11)}, \mathrm{F}_{(7)}\right)$ and $\left(\mathrm{Cl}_{(11)}, \mathrm{F}_{(9)}\right)$ as well as $\left(\mathrm{H}_{(2)}, \mathrm{F}_{(9)}\right)$ and $\left(\mathrm{H}_{(2)}, \mathrm{F}_{(7)}\right)$. In the case of $\mathrm{T}$ conformer, the closest pairs of atoms are $\left(\mathrm{Cl}_{(11)}, \mathrm{F}_{(9)}\right)$ and $\left(\mathrm{Cl}_{(11)}, \mathrm{F}_{(7)}\right)$, as well as $\left(\mathrm{Cl}_{(10)}, \mathrm{F}_{(9)}\right)$ and $\left(\mathrm{Cl}_{(10)}, \mathrm{F}_{(7)}\right)$.

According to the calculations, the repulsive interactions between chlorine and fluorine atoms are important in both conformers, whereas the interactions between hydrogen and fluorine atoms are comparatively very low (see Table 5). The sum of energies of the repulsive interactions in conformer $\mathrm{T}$ is approximately twice as large as those in conformer $\mathrm{G}$ (because the interactions with hydrogens are weak).

In the analysis presented above, we assumed the very simplistic approximation that atomic charges are point charges centered on the corresponding nuclei and this estimation of the Coulombic interactions should be treated only qualitatively. In the real molecule, the electronic density is distributed around the nuclei (see Figure 6) and the effective interaction energy should be lower. Nevertheless, this analysis reveals the presence of smaller repulsive interaction between the heavy atom groups $\mathrm{CCl}_{2} \mathrm{H}$ and $\mathrm{CF}_{3}$, in $\mathrm{G}$ conformer, and explains its higher stability relative to the $\mathrm{T}$ form.

\section{Conclusions}

The matrix-isolation infrared spectroscopic technique has been used, for the first time to the best of our knowledge, to study the spectra and structure of monomeric HCFC-243. In addition, the spectrum of the compound in the neat solid state at cryogenic temperatures was also studied and used to help interpreting the matrix-isolation data. In particular, it could successfully reveal some predicted low IR intensity bands that could not be observed otherwise. A detailed theoretical analysis facilitated the interpretation of the infrared spectra of the compound and the analysis of the conformational isomerism.

Potential energy profiles, calculated at the DFT(B3LYP) $/ 6-311++\mathrm{G}(\mathrm{d}, \mathrm{p})$ and MP2/6-311++G(d,p) levels of theory, revealed the existence of two different minima ( $G$ and $T)$, with the $\mathrm{G}$ form being the most stable form; the relative energy of the $\mathrm{T}$ form was calculated to be above $10 \mathrm{~kJ} \mathrm{~mol}^{-1}$, and its equilibrium population at room temperature was found to be $<1 \%$. In agreement with the calculations, only the $\mathrm{G}$ conformer was identified in the spectra of the solid and the matrix-isolated compound. A comparison of the experimental spectra with that calculated for the $\mathrm{G}$ conformer demonstrated the good agreement between them.

Natural bond orbitals (NBO) and APT charge analyses carried out for the two conformers of HCFC-243 revealed important details of their electronic structure and shed light on the most important intramolecular interactions responsible for their relative energy.

Acknowledgment. This work was funded by CAPES(Brazil)/ GRICES(Portugal) project No. 165/06 and the Portuguese Science Foundation (FCT; Project POCI/QUI/58937/2004). J.R.L., Jr., R.M.C.U.A., E.V., S.A. do M., C.F.B., and M.N.R. also acknowledge support from CNPq and FAPESQ (Brazilian agencies).

Supporting Information Available: Tables S1-S3 and Figure S1, as discussed in the text (ZIP). This material is available free of charge via the Internet at http://pubs.acs.org.

\section{References and Notes} 327.

(1) Hayman, G. D.; Derwent, R. G. Environ. Sci. Technol. 1997, 31,

(2) Berends, A. G.; de Rooij, C. G.; Shin-ya, S.; Thompson, R. S. Arch. Environ. Contam. Toxicol. 1999, 36, 146.

(3) Hasson, A. S.; Moore, C. M.; Smith, I. W. M. Int. J. Chem. Kinet. 1998, $30,541$.

(4) Saar, B. G.; Steeves, A. H.; Thoman Jr., J. W.; Howard, D. L.; Schofield, D. P.; Kjaergaard, H. G. J. Phys. Chem. A 2005, 109, 5323.

(5) Newnham, D.; Ballard, J. J. Quant. Spectrosc. Radiat. Transfer 1995, 53, 471.

(6) Di Lonardo, G.; Masciarelli, G. J. Quant. Spectrosc. Radiat. Transfer 2000, 66, 129.

(7) 1983 Report of the Technology and Economic Assessment Panel; United Nations Environment Programme: New York, July, 1993.

(8) Report of the Fourth Meeting of the Parties to the Montreal Protocol on Substances that Deplete the Ozone Layer, United Nations Environment Panel, New York, 1992.

(9) Sangchakr, B.; Hisanaga, T.; Tanaka, K. Chemosphere 1998, 36, 1985.

(10) Hashikawa, Y.; Kawasaki, M.; Andersen, M. P. S.; Hurley, M. D.; Wallington, T. J. Chem. Phys. Lett. 2004, 391, 165.

(11) Taketani, F.; Nakayama, T.; Takahashi, K.; Matsumi, Y.; Hurley, M. D.; Wallington, T. J.; Toft, A.; Andersen, M. P. S. J. Phys. Chem. A 2005, 109, 9061

(12) Andersen, M. P. S.; Nielsen, O. J.; Wallington, T. J.; Hurley, M. D.; DeMore, W. B. J. Phys. Chem. A 2005, 109, 3926.

(13) Frisch, M. J. Trucks, G. W.; Schlegel, H. B.; Scuseria, G. E.; Robb, M. A.; Cheeseman, J. R.; Montgomery, J., J. A.; Vreven, T.; Kudin, K. N. ; Burant,J. C.; Millam, J. M.; Iyengar, S. S.; Tomasi, J.; Barone, V.; Mennucci, B.; Cossi, M.; Scalmani, G.; Rega, N.; Petersson, G. A.; Nakatsuji, H.; Hada, M.; Ehara, M.; Toyota, K.; Fukuda, R.; Hasegawa, J.; Ishida, M.; Nakajima, T.; Honda, Y. ; Kitao,O.; Nakai, H.; Klene, M.; Li, X.; Knox, J. E.; Hratchian, H. P.; Cross, J. B.; Bakken, V.; Adamo, C.; Jaramillo, J.; Gomperts, R.; Stratmann, R. E.; Yazyev, O.; Austin, A. J.; Cammi, R.; Pomelli, C.; Ochterski, J. W.; Ayala, P. Y.; Morokuma, K.; Voth, G. A.; Salvador, P.; Dannenberg, J. J.; Zakrzewski, V. G.; Dapprich, S.; Daniels, A. D.; Strain, M. C.; Farkas, O.; Malick, D. K.; Rabuck, A. D.; Raghavachari, K.; Foresman, J. B.; Ortiz, J. V.; Cui, Q.; Baboul, A. G.; Clifford, S.; Cioslowski, J.; Stefanov, B. B.; Liu, G.; Liashenko, A.; Piskorz, P.; Komaromi, I.; Martin, R. L.; Fox, D. J.; Keith, T.; Al-Laham, M. A.; Peng, C. Y.; Nanayakkara, A.; Challacombe, M.; Gill, P. M. W.; Johnson, B.; Chen, W.; Wong, M. W.; Gonzalez, C.; Pople, J. A. Gaussian 03, revision C.02; Gaussian, Inc.: Wallingford, CT, 2004.

(14) Becke, A. D. J. Chem. Phys. 1993, 98, 5648.

(15) Lee, C. T.; Yang, W. T.; Parr, R. G. Phys. Rev. B 1988, 37, 785.

(16) Vosko, S. H.; Wilk, L.; Nusair, M. Can. J. Phys. 1980, 58, 1200.

(17) Moller, C.; Plesset, M. S. Phys. Rev. 1934, 46, 0618.

(18) Hehre, W. J.; Ditchfied, R.; Pople, J. A. J. Chem. Phys. 1972, 56, 2257

(19) Krishnan, R.; Binkley, J. S.; Seeger, R.; Pople, J. A. J. Chem. Phys. 1980, 72,650 .

(20) Schachtschneider, J. H.; Mortimer, F. S. Vibrational Analysis of Polyatomic Molecules. VI. FORTRAN IV Programs for Solving the Vibrational Secular Equation and for the Least-Squares Refinement of Force Constants. Project No. 31450. Structural Interpretation of Spectra; Shell Development Co: Houston, TX, 1965.

(21) Pulay, P.; Fogarasi, G.; Pang, F.; Boggs, J. E. J. Am. Chem. Soc. 1979, 101, 2550.

(22) Olbert-Majkut, A.; Reva, I. D.; Fausto, R. Chem. Phys. Lett. 2008, $456,127$.

(23) Kus, N.; Breda, S.; Reva, I.; Tasal, E.; Ogretir, C.; Fausto, R. Photochem. Photobiol. 2007, 83, 1237.

(24) Reva, I. D.; Jarmelo, S.; Lapinski, L.; Fausto, R. J. Phys. Chem. A 2004, 108, 6982 .

(25) Ivanov, A. Yu.; Plokhotnichenko, A. M.; Radchenko, E. D.; Sheina, G. G.; Blagoi, Yu. P. J. Mol. Struct. 1995, 372, 91.

(26) Breda, S.; Reva, I. D.; Lapinski, L.; Nowak, M. J.; Fausto, R. J. Mol. Struct. 2006, 786, 193.

(27) Weinhold, F.; Landis, C. R. Valency and Bonding. A Natural Bond Orbital Donor-Acceptor Perspective; Cambridge University Press: New York, 2005.

(28) Mulliken, R. S. J. Chem. Phys. 1955, 23, 1833.

(29) Reed, A. E.; Weinstock, R. B.; Weinhold, F. J. Chem. Phys. 1985, 83,735 .

(30) Cioslowski, J. J. Am. Chem. Soc. 1989, 111, 8333.

(31) Freeman, F.; Po, H. N.; Ho, T. S.; Wang, X. M. J. Phys. Chem. A 2008, 112, 1643 .

JP807388A 